http://jmscr.igmpublication.org/home/ ISSN (e)-2347-176x ISSN (p) 2455-0450

crossref DOI: https://dx.doi.org/10.18535/jmscr/v7i11.16

\title{
The Incidence and Prevalence of Hypertension in Patients Attending OP of Annapoorna Medical College and Hospital, Salem
}

\author{
Authors \\ Dr S.Senthilnathan MD ${ }^{1}$, Dr M.N. Shamala ${ }^{2^{*}}$ \\ ${ }^{1}$ Associate Prof, Medicine, ${ }^{2}$ Assistant Prof, Medicine \\ *Corresponding Author \\ Dr M.N. Shamala
}

\begin{abstract}
Hypertension is a major health problem which affects most of the people in the world and it needs so importance because it causes major risk factors which cause various complications.

Objectives

1. To know the incidence and prevalence of hypertension.

2. Assessment of patient's knowledge, attitude and practice regarding hypertension.

Materials and Method: The study is to be conducted among the patients attending op of annapoorana medical college and hospital, salem, spread over three month April-June 2019. A total of 200 patients could be studied over this period. The aim of this study was to explore the prevalence and awareness of hypertension A suitably designed and validated KAP questionnaire was administered to hypertensive patients. This questionnaire was filled in at face to face interview along with inform consent Results. Around $18.2 \%$ of patients using tobacco are hypertensive. Person more than 35 years are hypertensive than those less than 35 years.

Conclusion: There is significant burden of hypertension in areas around annapoorana medical college and hospital, salem. Independent risk factors of hypertension are age, education, and levels of cholesterol. The patient should be educated about the importance of the physical activity.

Keywords: Hypertension, KAP.
\end{abstract}

\section{Introduction}

Hypertension is a health problem in majority of the public due to its increase prevalence all around the globe. Around 8 million deaths or $13.8 \%$ of the total of all deaths which occur in the world due to high blood pressure. It is obvious that it increase to 1.56 billion adults with hypertension in 2030. Raised blood pressure is a major risk factor for chronic heart disease, stroke, and coronary heart disease. Elevated BP is the risk factor of stroke and coronary heart disease. Other than coronary heart disease and stroke, its complications include heart failure, peripheral vascular disease, renal impairment, retinal hemorrhage, and visual impairment.

Non communicable diseases, especially Coronary Artery Disease (CAD) including hypertension is a major risk factor that accounts for almost $45 \%$ to $50 \%$ of deaths CAD are nowadays increasingly seen in working people in age group of 30-65 years. Blood pressure is the single most useful test for identifying individuals with CAD. Studies in the past show a prevalence of hypertension to be $4-8 \%$ in adults and a little higher in urban population $16.6 \%$. Such a high morbidity and mortality has generated concerns among general population. 
Blood pressure generally tends to rise with age. Heredity and obesity also play a important role in the development of hypertension. The common modifiable risk factors for hypertension is due to consumption of high fat and sedentary life style, smoking, alcoholism, stress, etc. These factors are related to each other such that appearance of one factor paves the way for CAD. Therefore prevention of primary risk factors and its early diagnosis and treatment will delay noncommunicable diseases and CAD. In India according to current trends number of deaths by non-communicable diseases would increase from 4.8 million in 1990 ( $45 \%$ of all deaths) to 8.5 million in 2020 ( $73 \%$ of all deaths).

\section{Objectives}

1. To know the incidence and prevalence of hypertension among the patients attending annapoorna medical college and hospital salem.

2. Assessment of patient's knowledge, attitude and practice regarding hypertension.

\section{Materials and Method}

The study is to be conducted among the patients attending op of annapoorana medical college and hospital, salem spread over three month April June 2019. A total of 200 patients could be studied over this period. The subjects were interviewed and clinical examination was done including measurement of blood pressure, height and weight, after obtaining their consent. Blood pressure was measured by mercury sphygmomanometer. Two readings were taken at an interval of 10-15 minutes and the lower reading was considered for the purpose of this study. Height in centimeters and weight in kilograms was measured with standard clothing. According to JNC 7 criteria, if systolic BP is $>140$ or equal to $140 \mathrm{~mm} \mathrm{hg}$ or if diastolic BP $>90$ or equal to $90 \mathrm{~mm} \mathrm{hg}$ or if already on anti-hypertensive treatment was considered to be hypertensive. The aim of this study was to find the prevalence and awareness of hypertension.

A total of 200 hypertensive patients with or without comorbid condition were included. Adults of age more than 30 years were selected and this study was done by simple random sampling method. To find out whether the patient are aware of complication of uncontrol hypertension. A total of 21 questions were framed, with 8 questions related to knowledge about hypertension, 6 questions to assess the attitude of the patient towards hypertension and 7 questions regarding practice.

\begin{tabular}{|l|c|c|}
\hline & SBP $(\mathrm{mmHg})$ & DBP $(\mathrm{mmHg})$ \\
\hline Normal & $<120$ & $<80$ \\
\hline Prehypertension & $120-139$ & $80-89$ \\
\hline Stage 1 & $140-159$ & $90-99$ \\
\hline Stage 2 & $>160$ & $>100$ \\
\hline
\end{tabular}

JNC-7, the Seventh Report of the Joint National Committee on Prevention, Detection, Evaluation, and Treatment of High Blood Pressure; SBP, systolic blood pressure; DBP, diastolic blood pressure.

\section{Analysis}

Table .1 Sociodemographic characteristics of the study subjects.

\begin{tabular}{|l|c|c|c|c|c|}
\hline \multirow{2}{*}{ Variable } & \multirow{2}{*}{ Subgroups } & \multicolumn{4}{|c|}{ Group } \\
\cline { 2 - 5 } & & \multicolumn{2}{|c|}{ Non hypertensive } & \multicolumn{2}{c|}{ Hypertensive } \\
\hline Gender & $\mathrm{n}=1180$ & $\mathrm{n}=200$ & 14.4 \\
& Male & 455 & 85.6 & 76 & 124 \\
\hline Age & Female & 725 & 85.4 & 28 & 4.7 \\
& Less than 35 years & 580 & 95.3 & 172 & 22.2 \\
\hline Religion & More than 35 years & 600 & 77.8 & 193 & 14.4 \\
& Hindu & 1152 & 85.6 & 7 & 20 \\
\hline Education level & Others & 28 & 80 & 124 & 11.4 \\
& Literate & 966 & 88.6 & 76 & 26.3 \\
\hline Occupation & Illiterate & 214 & 73.7 & 179 & 14.9 \\
& Stressless & 1001 & 85.1 & 21 & 10.5 \\
\hline
\end{tabular}




\section{Figure 1}

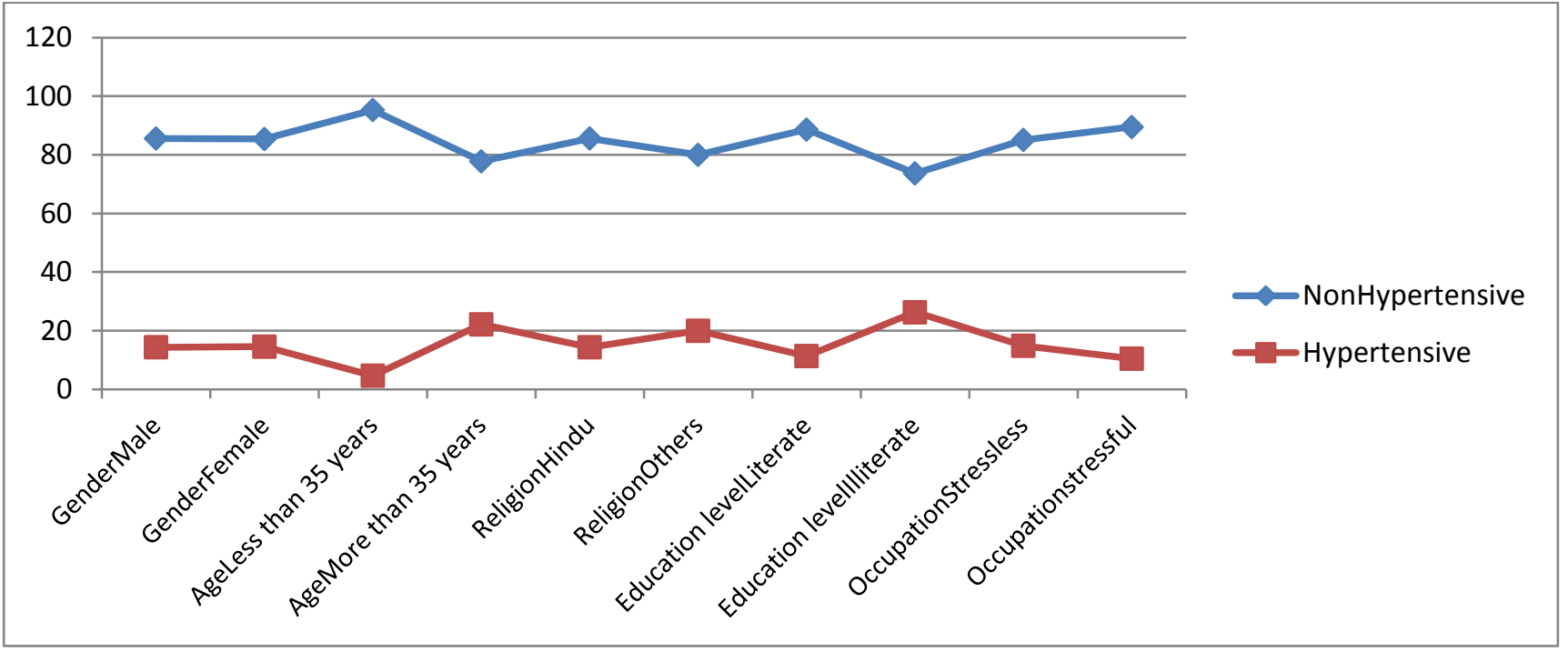

Table 2 Risk factors of study subjects

\begin{tabular}{|l|c|c|c|c|c|}
\hline \multirow{2}{*}{ Variable } & \multirow{2}{*}{ Subgroups } & \multicolumn{4}{|c|}{ Group } \\
\cline { 3 - 6 } & & \multicolumn{2}{|c|}{ Non hypertensive } & \multicolumn{2}{c|}{ Hypertensive } \\
\hline Tobacco Use & Yes & 124 & 81.5 & 28 & 18.5 \\
& No & 1056 & 85.9 & 172 & 14.1 \\
\hline Alcohol Use & Yes & 62 & 74.6 & 21 & 25.4 \\
& No & 1118 & 86.1 & 179 & 13.9 \\
\hline Total Cholesterol & Raised & 338 & 78.9 & 90 & 21.1 \\
& Normal & 842 & 88.4 & 110 & 11.6 \\
\hline HDL & Raised & 1124 & 85.3 & 193 & 14.7 \\
& Normal & 56 & 88.8 & 7 & 11.2 \\
\hline Triglycerides & Raised & 241 & 81.4 & 55 & 18.6 \\
& Normal & 939 & 86.6 & 145 & 13.4 \\
\hline \multirow{3}{*}{ Body Mass } & Underweight & 131 & 90.3 & 14 & 9.7 \\
Index & Normal & 372 & 88.5 & 48 & 11.5 \\
& Overweight & 179 & 76.4 & 55 & 21.5 \\
& Obese & 498 & 85.7 & 83 & 14.3 \\
\hline
\end{tabular}

\section{Figure 2}

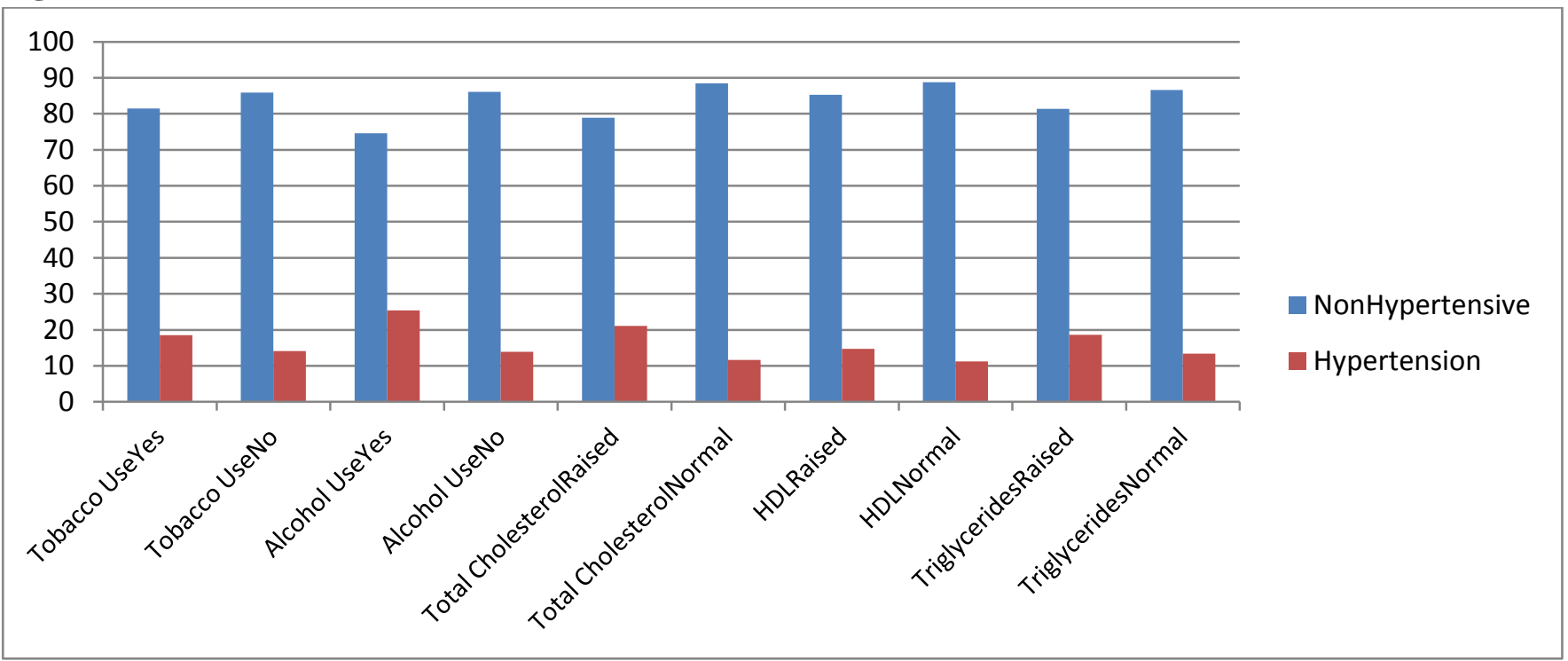


Table 3: Attitude questions

\begin{tabular}{|l|c|c|c|}
\hline Do you think regular medications will improve the & Yes & 179 & 89.5 \\
disease & No & 21 & 10.5 \\
\hline Do you think medications alone can control HTN & Yes & 180 & 90 \\
& No & 20 & 10 \\
\hline Do you think diet control will improve the condition & Yes & 116 & 58 \\
& No & 84 & 42 \\
\hline Do you think salt reduction can control hypertension & Yes & 133 & 66.5 \\
& No & 67 & 33.5 \\
\hline Do you think regular physical activity is essential & Yes & 73 & 36.5 \\
& No & 127 & 63.5 \\
\hline Avoiding extra cooking oil & Yes & 109 & 54.5 \\
& No & 91 & 45.5 \\
\hline
\end{tabular}

Table 4: Knowledge related questions

\begin{tabular}{|l|c|c|c|}
\hline How did you come to know about your htn & Clinical & 169 & 84.5 \\
& voluntary & 31 & 15.5 \\
\hline Do you have any relatives with history of htn- & Yes & 53 & 26.5 \\
& No & 147 & 73.5 \\
\hline Do you know what are the complications of htn & Yes & 48 & 24 \\
& No & 152 & 76 \\
\hline Do you know normal level of blood pressure & Yes & 104 & 52 \\
& No & 96 & 48 \\
\hline Do you know the symptoms of htn & Yes & 65 & 32.5 \\
& No & 135 & 67.5 \\
\hline Do you think smoking and alcohol consumption & Yes & 114 & 57 \\
cause htn & No & 86 & 43 \\
\hline Do you think obesity is associated with htn & Yes & 93 & 46.5 \\
& No & 107 & 53.5 \\
\hline Do you know the names of your prescribed drugs & Yes & 60 & 30 \\
& No & 140 & 70 \\
\hline
\end{tabular}

Table 5: Practice related questions.

\begin{tabular}{|c|c|c|c|}
\hline Where you was first diagnosed with HTN & $\begin{array}{l}\text { Government } \\
\text { Private }\end{array}$ & $\begin{array}{c}91 \\
109 \\
\end{array}$ & $\begin{array}{l}45.5 \\
54.5 \\
\end{array}$ \\
\hline Regular Follow up & $\begin{array}{l}\text { Yes } \\
\text { No }\end{array}$ & $\begin{array}{c}129 \\
71 \\
\end{array}$ & $\begin{array}{l}64.5 \\
35.5 \\
\end{array}$ \\
\hline Did you ever experienced any side effect & \multicolumn{3}{|c|}{ Did you ever experienced any side effect } \\
\hline Did you ever taken double dose & $\begin{array}{l}\text { Yes } \\
\text { No }\end{array}$ & $\begin{array}{c}6 \\
194\end{array}$ & $\begin{array}{c}3 \\
97\end{array}$ \\
\hline Are you avoiding extra added salt & $\begin{array}{l}\text { Yes } \\
\text { No }\end{array}$ & $\begin{array}{c}122 \\
78\end{array}$ & $\begin{array}{l}61 \\
39\end{array}$ \\
\hline Are you doing any physical exercise daily & $\begin{array}{l}\text { Yes } \\
\text { No }\end{array}$ & $\begin{array}{c}33 \\
167\end{array}$ & $\begin{array}{r}16.5 \\
83.5\end{array}$ \\
\hline Are you taking your drugs regularly & $\begin{array}{l}\text { Yes } \\
\text { No }\end{array}$ & $\begin{array}{c}129 \\
71\end{array}$ & $\begin{array}{l}64.5 \\
35.5 \\
\end{array}$ \\
\hline
\end{tabular}

\section{Discussion}

The prevalence of hypertension was $14.4 \%$ (200/1380) among study subjects. Table 1 shows the socio demographic characteristics such as age, sex, and religion of non hypertensive $(n=1180)$ and hypertensive $(n=200)$ groups. The hypertension was found out to be more in individual with age group more than 35 years. There was significant difference between the two groups with respect to age. The majority of hypertensive patients in my study are female $14.6 \%$. Table 2 shows about the risk factors of both hypertensive and non hypertensive groups. From this study we can clearly see that there was no significant difference in tobacco intake.

The hypertension was significantly higher in individual who consumes alcohol. Cholesterol levels were measured among study subjects. 
Hypertension was found in $21 \%$ of subjects with raised total cholesterol level and $11.6 \%$ among those with normal values. Similarly there was difference in raised triglyceride levels in the both groups. A significantly higher number of study subjects were hypertensive overweight and obese group as compared to the other group. Table 3 is question related to knowledge in which we found out that patient is not aware of symptoms $67.5 \%$ and complications of hypertension $76 \%$ were as they are aware of normal blood pressure $52 \%$ and the side effects of smoking and alcohol in related to hypertension $57 \%$ from this table it clearly shows patient is not aware of control blood pressure .Table 4 shows that patients are aware of taking regular medication $89.5 \%$ and importance of diet control $58 \%$ and $63.5 \%$ are not aware of importance of physical activity which is useful for treatment for hypertension.

\section{Conclusion}

From this study we can concluded that the prevalence of hypertension is high in area around annapoorna medical college and hospital salem. So the people around this area are vulnerable to several chronic diseases and other unbearable health problem. Specifically females are more risk of being hypertensive than male.. Independent risk factor for hypertension was found out to be increasing age. Weight management, increased fruits and vegetables consumption, physical activity and reduction in tobacco and alcohol use are required and recommended. The subject had poor knowledge on hypertension. So people requires awareness about complication of hypertension, regular use of medication and physical activities.

\section{References}

1. Ahmed A., Rahman M., Hasan R., et al. Hypertension and associated risk factors in some selected rural areas of Bangladesh. International Journal of Research in Medical Sciences. 2014; 2(3):p. 925. doi: 10.5455/2320- 6012.ijrms20140816. [CrossRef] [Google Scholar]

2. Abebe S. M., Berhane Y., Worku A., Getachew A. Prevalence and associated factors of hypertension: a crossectional community based study in Northwest Ethiopia. PLoS ONE. 2015;10(4) doi: 10.1371/journal.pone.0125210.e0125210 [ PMC free article] [PubMed] [CrossRef] [Google Scholar]

3. Erem C., Hacihasanoglu A., Kocak M., Deger O., Topbas M. Prevalence of prehypertension and hypertension and associated risk factors among Turkish adults: trabzon hypertension study. Journal of Public Health. 2009;31(1):47-58. doi: 10.1093/pubmed/fdn078. [PubMed] [CrossRef] [Google Scholar]

4. Mishra C. P., Kumar S. Risk factors of hypertension in a rural area of Varanasi. Indian Journal of Preventive and Social Medicine. 2011;42(1):101111. [Google Scholar]

5. Mendis S. World Health Organisation; 2010. Global status report on non communicable diseases 2010. http://www.who.int/nmh/publication s/ncd_report2010/en/ [Google Scholar]

6. Tabrizi J. S., Sadeghi-Bazargani H., Farahbakhsh M., Nikniaz L., Nikniaz Z. Prevalence and associated factors of prehypertension and hypertension in Iranian population: the lifestyle promotion project (LPP) PLoS ONE. 2016;11(10) doi:

10.1371/journal.pone.0165264.e0165264 [ PMC free article] [PubMed]

7. Y.Huang, S.Wang, X.Cai et al., "Prehypertension and incidence of cardiovascular disease: a meta-analysis," BMC Medicine, vol.11, article 177, 2013.

8. M.-J. Kim, N.-K. Lim, and H.-Y. Park, "Relationship between prehypertension and chronic kidney disease in middle-aged people in Korea: the Korean genome and 
epidemiology study," BMC Public Health, vol. 12, article 960, 2012.

9. S. S. Lim, T. Vos, A. D. Flaxman et al., "A comparative risk assessment of burden of disease and injury attributable to 67 risk factors and risk factor clusters in 21 regions, 1990-2010: a systematic analysis for the Global Burden of Disease Study 2010," The Lancet, vol. 380, no. 9859, pp. 2224-2260, 2012.

10. J. Kishore, National Health Programs of India, Century Publications, NewDelhi, India, 11th edition, 2014.

11. Y. S.Kusuma, S. K. Gupta, and C. S. Pandav, "Treatment seeking behaviour in hypertension: factors associated with awareness and medication among socioeconomically disadvantaged migrants in Delhi, India," Collegium Antropologicum, vol. 37, no. 3, pp. 717722, 2013.

12. R. J. Khan, C. P. Stewart, P. Christian et al., "A cross-sectional study of the prevalence and risk factors for hypertension in rural Nepali women," BMC Public Health, vol. 13, article 55, 2013. 